\title{
An Actor's Process in Performing the Role of Tom Wingfield in Tennessee Williams' "The Glass Menagerie"
}

\author{
Beau Harris
}

Follow this and additional works at: https://researchrepository.wvu.edu/etd

\section{Recommended Citation}

Harris, Beau, "An Actor's Process in Performing the Role of Tom Wingfield in Tennessee Williams' "The Glass Menagerie"'" (2015). Graduate Theses, Dissertations, and Problem Reports. 5768.

https://researchrepository.wvu.edu/etd/5768

This Thesis is protected by copyright and/or related rights. It has been brought to you by the The Research Repository @ WVU with permission from the rights-holder(s). You are free to use this Thesis in any way that is permitted by the copyright and related rights legislation that applies to your use. For other uses you must obtain permission from the rights-holder(s) directly, unless additional rights are indicated by a Creative Commons license in the record and/ or on the work itself. This Thesis has been accepted for inclusion in WVU Graduate Theses, Dissertations, and Problem Reports collection by an authorized administrator of The Research Repository @ WVU. For more information, please contact researchrepository@mail.wvu.edu. 
An Actor's Process in Performing the Role of Tom Wingfield in Tennessee Williams' The Glass Menagerie

Beau Harris

\begin{abstract}
Thesis submitted to the College of Creative Arts at West Virginia University in Partial fulfillment of the requirements for the degree of
\end{abstract}

\author{
Master of Fine Arts \\ in \\ Theatre (Acting Cocentration) \\ Jay Malarcher, PhD, Associate Professor, Chair \\ Jerry McGonigle, MFA, Professor/Head of Graduate Acting \\ Jim Knipple, MFA, Assistant Professor \\ General McArthur Hambrick, MFA, Assistant Professor of Acting
}

School of Theatre \& Dance

Morgantown, West Virginia

2015

Keywords: The Glass Menagerie; Tennessee Williams; Tom Wingfield; Actor; Process; Improv; Improvisation 


\section{ABSTRACT \\ An Actor's Process in Performing the Role of Tom Wingfield in Tennessee Williams' The Glass Menagerie \\ Beau Harris}

The following pages will chronicle my experience of discovering The Glass Menagerie, as well as my development of the character of Tom for a production at West Virginia University under the direction of Kathleen Amshoff. I will walk you though my experience from the day I was cast to the very last show by describing to you my research, the rehearsal process, outcomes of the process, and finally my evaluation of the production as well as my own work. 


\section{Table of Contents}

TITLE PAGE

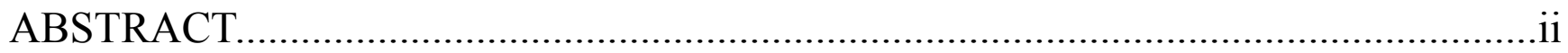

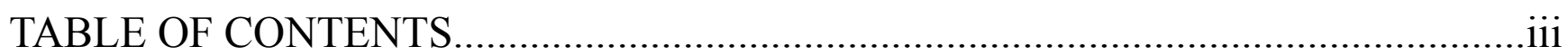

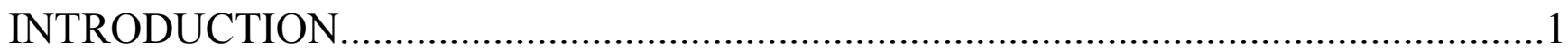

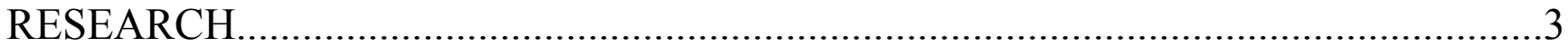

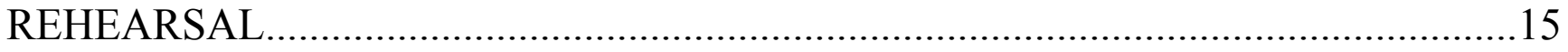

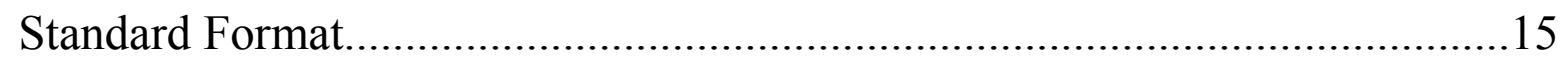

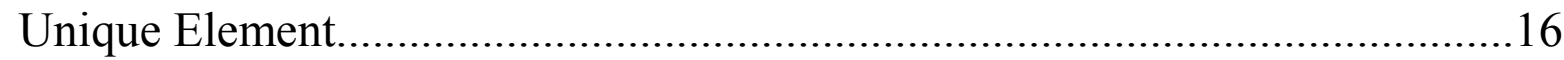

Goals, Focuses, Achievements and Challenges............................................21

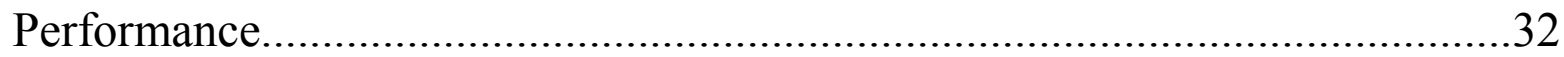

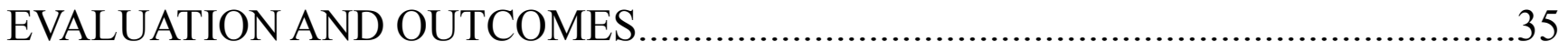

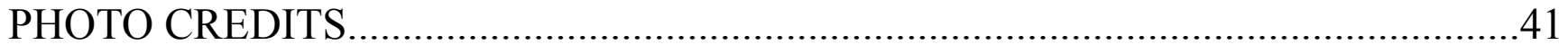

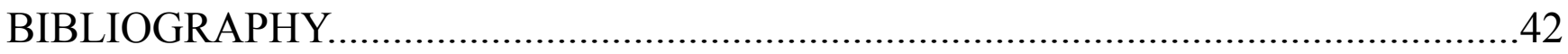




\section{Introduction}

The following is an exploration of my development and performance of the role of Tom Wingfield for the purposes of fulfilling the thesis requirement for the Master of Fine Arts in Theatre with an Acting emphasis at West Virginia University. In order to document my process, I kept a detailed journal tracking my journey in finding Tom from the day I was cast until the closing night of the performance. The following detailing of my specific process in the interpretation, creation, and performance of my Tom Wingfield comes completely from this journal augmented by my personal memory.

In my time at WVU, the building of a concrete and broadly applicable process has been one of my primary objectives. The work completed in fulfillment of my classes as well as for the shows here at WVU has triggered a major advance in my approach to acting. Most notably I have noticed great improvements in my overall confidence as an actor on and off stage, my clarity and strength of voice and speech, my overall physical awareness, and, most importantly, my knowledge of myself and how to use that knowledge to my advantage when building and performing characters for any given show. When comparing my process prior to attending WVU to where I am now, I find that I still tend toward working in a focused and internal manner, though, thanks to my training and experiences here, a much needed sense of play has begun to emerge. In order to further the depth of both this sense of play and my connection to any given character, I have also spent much time cultivating the ability to find the connections between myself and a character in order to allow the character to root them-self within me. The role of Tom provided the perfect opportunity for me to focus deeply on these two areas of my process, thereby allowing me to fully give in to Tom as much of Tom's life, family, and dilemmas mirror that of my own from a past portion of my life.

In order to give a full picture of my process for developing the character of Tom Wingfield, I 
will be breaking down the work I did for inhabiting his life from the very first day of rehearsals to the last performance. I will focus primarily on the areas of:

Research - This section will outline my preparation and background work for the role as well as the world of the play.

Rehearsal - This section will follow my work throughout the rehearsals and highlight the key work that led to the performative version of Tom.

Performance - This section will chronicle the challenges faced, evolutions achieved, and present reflections of each of the individual performances.

Evaluation and Outcomes- This section will be a reflective analysis of my feelings about my work including, strengths, weaknesses, successes, failures, as well as what it taught me about my self and my processes, and what lessons I can carry forward to future projects from this experience.

This process was an extremely beneficial and transformative experience for me as both an actor and an individual. Such a journey can be difficult to recount, no less put to paper, in a meaningful way that will truly allow a reader to enter the inner landscape of my emotional, mental, and physical experience. That said, the following work will at least provide the most in-depth look possible by way of the written word. 


\section{$\underline{\text { Research }}$}

As with any show, my process began with research. As I was cast in the show only a few days before the start of rehearsals due to extenuating circumstances, I was unable to devote too much time to the research process. This meant that I had to work quickly and identify the key components of knowledge and experience that I was lacking. As the most essential piece of research for every role is that of the first reading of the text itself, that is where I began. This first reading made many research necessities come to light immediately, the first of which was inspired by the depth of the family bonds of the Wingfields. The ability to understand and live these bonds is, to me, essential in order to find the full emotional breadth of the character and to relay all layers of the story to the audience in an accurate and meaningful manner. Knowing that and given that the Wingfield's bonds are so strong and complex, it was clear to me that replicating those bonds would require a great deal of rapport with the actresses playing my mother and my sister. This can only be accomplished by spending time with, learning about, and closely interacting with those that will complete the ensemble of the stage family. Fortunately, the actress playing my mother, Stephanie Freeman, is a member of the MFA cohort, so we already had a fairly deep rooted though often rocky relationship that stems from close personal interaction on a day-to-day basis, so the groundwork for that relationship was already two years in the making. The actress playing my sister, Aubrey Rice, however, was someone I had had very little interaction with on or off stage, so, it was clear that additional time would need to be spent to build a personal relationship with her that we could both draw on for an otherwise unreachable depth of relationship. This kind of relationship with one's fellow actors also generally helps in building trust and understanding of each other which can lead to a greater sense of play, fearlessness, and ultimately a strong and specific emotional acuity from which we can effectively and realistically respond to each other's behavior on stage. Without these things, I have found, there is generally a ceiling of 
"competent" on the overall performances given in a show by the actors as the intangible connections, details, and feelings are missed. Unfortunately, due to our hectic and often mismatched schedules, our bonding time was relegated to rehearsals and a few rides home. From these interactions, I gathered as much as I could and used them to fuel my creative imagination and combined that with my experiences with my own sister in order to build the best familial relationship that I could. Though this time did allow us to build a rapport, there was clearly a level of strength and emotionality that we never quite reached in our relationship that could have been greatly expanded upon had we been able to spend the time getting to really connect on a personal level outside of the theatre and the world of the play.

My first reading also lead to a slew of other questions and more traditional research prompts that warranted further investigation in order to begin building a real and off the page beginning understanding of Tom Wingfield and the world both within and around him. These questions ranged widely and covered a wide array of subjects. Below are some of the most prominent research prompts that arose from this initial read and carried through the rest of the process:

\section{What brand and type of cigarettes does Tom smoke?}

Though this may seem like a trivial detail to many, I've never met a smoker that did not have a strong conviction about their choice in smokes. Being that smoking is one of the very few escapes and luxuries that Tom has in his life, I felt that it was a very important part of building his character as well as an excellent detail from which I could begin my investigation of who Tom really is. My initial instinct, which we ended up going with for the final production, was that Tom is a roll-your-own type of smoker. Not only did roll your own cigarettes fit Tom very well in my interpretation, it gave me a very specific activity to focus on and accomplish on stage, which always helps to ground me as an actor.

\section{What is Tom's job at the shoe factory and what is a shoe factory like at that time?}

Since the factory is where Tom spent the majority of his waking hours during the time frame of 
his life that The Glass Menagerie covers, it seemed imperative to me to know what he would be coming from and going to everyday. Though the text doesn't tell us what exactly Tom does at the factory, though it does give us a brief insight in scene three when Tom describes his workplace as a "celotex interior with florescent tubes" ( $\mathrm{p} .23)^{1}$, a rather drab image. The most impactful insights that came in answering this question came in the form of photographs (see examples below) and my own personal experience working in warehouses.

\section{The world that shaped Tom.}

Tom presents himself as up-to-date and socially aware of the world he is living in. In the play, he mentions some very specific major international events centered primarily around the Spanish Civil War, so I set a task for myself to pay special attention to the events and objects that Tom mentions in the text, such as Guernica (interestingly both an event and an object), to find the meaning of his attachment to these specifics as well as deepen my understanding of the things that were happening at the time that Tom himself found to be the most fascinating and affecting. This was perhaps one of the most enjoyable portions of my research as it allowed me to spend some time reacquainting myself with a period of history that has always fascinated me.

\section{What is the meaning of the title?}

Knowing the works of Tennessee Williams, it seemed unlikely to me that he simply titled the play after Laura's menagerie in the play. During my reading of Lyle Levrich's biography of Tennessee Williams, entitled Tom: The Unknown Tennessee Williams, I learned that one of his childhood neighbors, Mrs. Wingfield (Tom's family's namesake), had a glass menagerie in her front window that Tom used to stare at for hours on end. Mrs. Wingfield's menagerie always stuck with Tom and was a natural choice for inclusion as the title piece of his largely autobiographical play. Beyond the emotional significance of the menagerie from his past, the word menagerie itself stands out poignantly as a

1 All script quotations originate from: Williams, Tennessee. The Glass Menagerie. New York: Dramatists Play Service, 1976. Print. 
reference to the ghost-like window the memories presented in this play provide us to a very caged period in both Tom's and, by extension, Williams' life.

\section{What is Tom's past like?}

This section became a great focus for me given the prevalence of Tom's non-present father and the clear and definite influence that had on his life as well as the deep family dynamics and adventurous desires that have clearly been building within Tom for years. Since none of this is rooted in the concrete or factual, the majority of my work here came in the form of improvs (which will be discussed later in this section), imagination, and drawing on similarities that Tom and I share in our desires for adventurers, non-traditional families, and black sheep status within a household that consists of mother, sister, and self.

\section{How do I explain the memory of scenes Tom was not present for?}

This is one of the more baffling techniques used by Williams in this play. Though The Glass Menagerie is a self-pronounced memory play, the presentation of scenes that go beyond the possible scope of experience of its declared narrator (Tom) creates a very interesting challenge for the narrator of the story in how were these "memories" created or assembled, and what degree of bias/audience steering does this contain or allow for? The justification I chose to work with was that, due to the close nature of Tom and Laura's relationship as well as the chattiness of his mother, Tom likely got the basics for each of these events from his mother and sister. From here I believe that Tom took the given details conveyed to him and combined it with his own intimate knowledge of the individuals involved and their relationships and supposed the details from there in his imagination in order to paint the full and detailed picture of each of these scenes for the audience.

\section{How does Tom feel about each character?}

This question would become one of the primary focal points for each character in developing the show throughout the rehearsal process. Our Director, Kathleen Amshoff, really pushed each actor to 
explore all of the shades of our relationships with each character, particularly within the Wingfield family. The most complicated of these relationships, for me, was between Tom and Amanda which, aside from a few disarmed moments, appears as a cavalcade of negative and hostile emotions and interactions. The problem with that, however, is that if played in that manner (as I have seen done in several other productions), we lose the true complexity that forms in any familial relationship. Despite the angst, there is love between Tom and Amanda, as witnessed by Tom taking on the role of primary provider for her and his sister and by the fact that it takes him so long to leave the house; if there is no love (and to an extent guilt) holding him there, then why does he stay? The development and specifics of these relationships will be explored in greater depth throughout this paper.

\section{Why is Tom telling this story?}

Every story is told for a reason though the reason is not always clear. The specific intent of an individual to say what they say is not often specifically stated, particularly in a stylized and poetic work like The Glass Menagerie. In examining the text both myself and with Amshoff, I found that the more time I spent with the script the more I felt that it had a certain quality of penance to it. Talking this idea over with Amshoff, we came to agree that, among some other possible motivations, Tom's chief reason for telling the story is to think through this period, present it for the jury of the audience in a way of seeking either approval or forgiveness for his justifications for living and leaving as he did. Tom presents his story in a way that hopes to inspire understanding from his listeners, but without making himself out to be an angel so as to present, in the best way he can, his true and realistic self as seen through his own eyes. In doing so, Tom drives through this story towards absolution from himself and, as shown in the final scene, the specter of Laura who has haunted him since he left. By the end of the story he leaves his dramatized confessional to try to continue down the path he has forged with a little less weight on his heart. 
dominates his inner life and outer-life and how will I use this as a tool for letting the audience in to my world or strategically shut them out?

With a story that is as personal in nature to Tom as The Glass Menagerie and because of the reasons I believe he is telling it, I had to walk a very fine line between open and vulnerable truth, and masking. After all, Tom presents himself to the audience as a stage magician who gives us "truth in the pleasant disguise of illusion" (p.11). This acknowledgment combined with the fact that no matter how truthful and honest Tom wants to be with his portrayals (and I believe that, with the exception of adding a bit of color and fantasy, particularly to the scenes that he himself was not present for, he does want to be truthful), lead to the truth that it is impossible for one to give a completely fair and disconnected third person account of themselves and their actions, particularly when it comes to negative or highly emotional situations. With that in mind, I did my best to embody this truth and allow myself to present the story with the tacit admission of this fact in place for the audience throughout.

\section{Based on this initial read, what elements of my personal life can I use to connect to this character} and his world?

This, to me, is one of the most important questions that an actor can ask themselves in order to work toward building a truthful, rooted, and multidimensional character. The inner life and specificity of a complete being that we, as actors, can provide our characters by allowing our personal worlds to meld with theirs in any way possible is one of the scariest and most vulnerable things that we can do, as it puts more than just a character on stage, it puts elements of our true inner self, but it is also one of the most powerful and liberating things that we can do. I struggled with this melding of personalities as Tom is one of the closest to my personal life characters that I have ever played. Some of the experiences that Tom and I share that I used to root my work for this show include:

- $\quad$ Tom and I both have a strong tendency for wanderlust.

- Tom and I have both spent time in St. Louis as well as working in factory/warehouse related 
occupations.

- Tom and I both felt a strong need to leave our homes and families in our twenties.

- The relationship dynamic between Tom and his mother are very similar to that of mine with my own from my early teens until right around the time of this show.

- Half of my life was also spent in a fatherless home with my sister and my mother.

- There are many similarities to my relationship with my father, and who I have become in relation to him, that very much mirror Tom's experiences with his father.

- I have dealt with many of the feelings that affect Tom throughout the play in regards to not fitting in, being misunderstood, and not appreciated within my family.

With this initial research list in place on the first day, I began to dive deeper into the character of Tom. In doing so, I paid special attention to the personal contexts of his world as well as the early life of Tennessee Williams, given that Tom has been noted to be a somewhat stylized autobiographical account of William's own life. In order to accomplish this I did some general, cursory research online, diving into many articles on labor in the '30s, paying particular attention to photos. The following four photos were the ones that struck me most in my image research and that I would most often return to for inspiration. I found them to embody sufficiently the time period as well as Tom's specific mindset as to his reality very well.

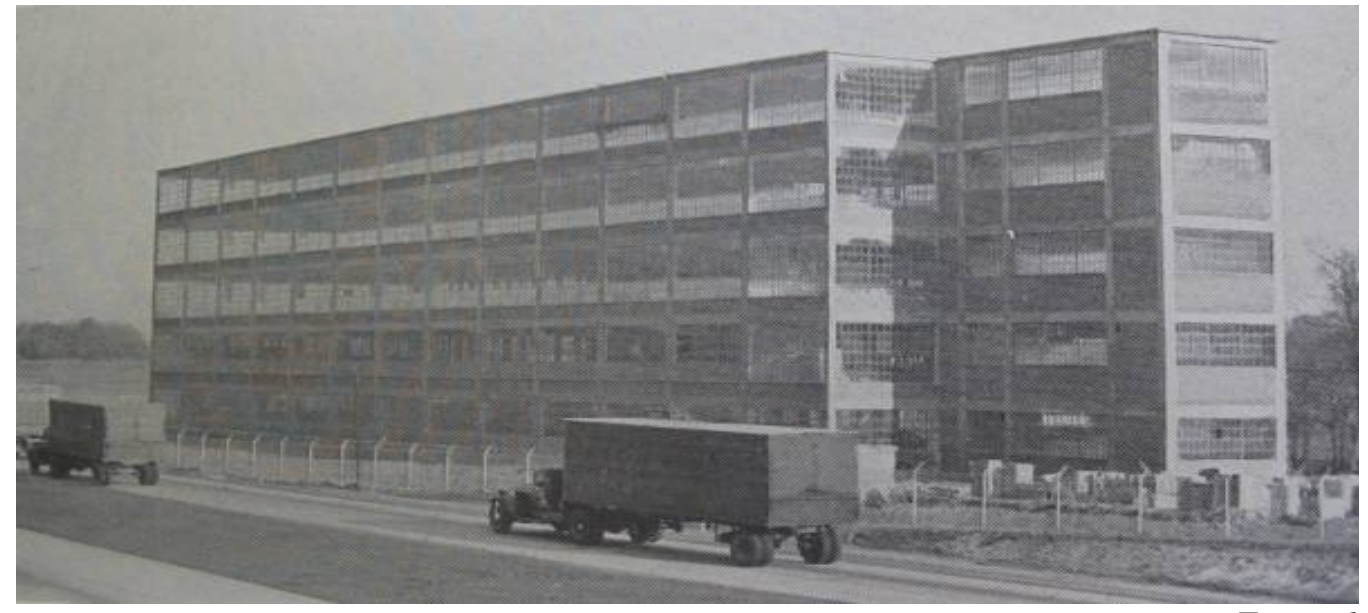




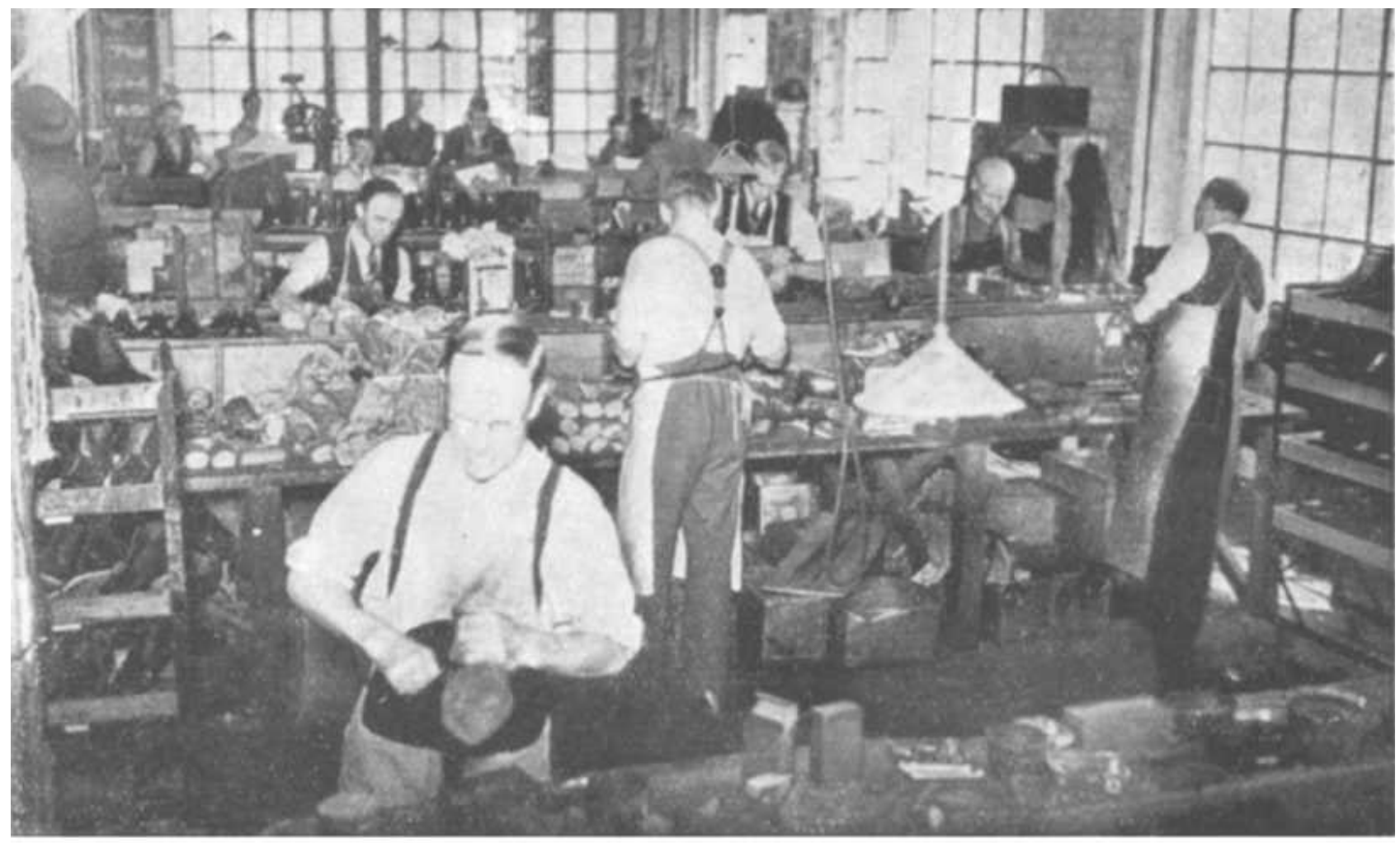

Handworkers on heavy boots, Hannah's, Wellington.

Figure 2

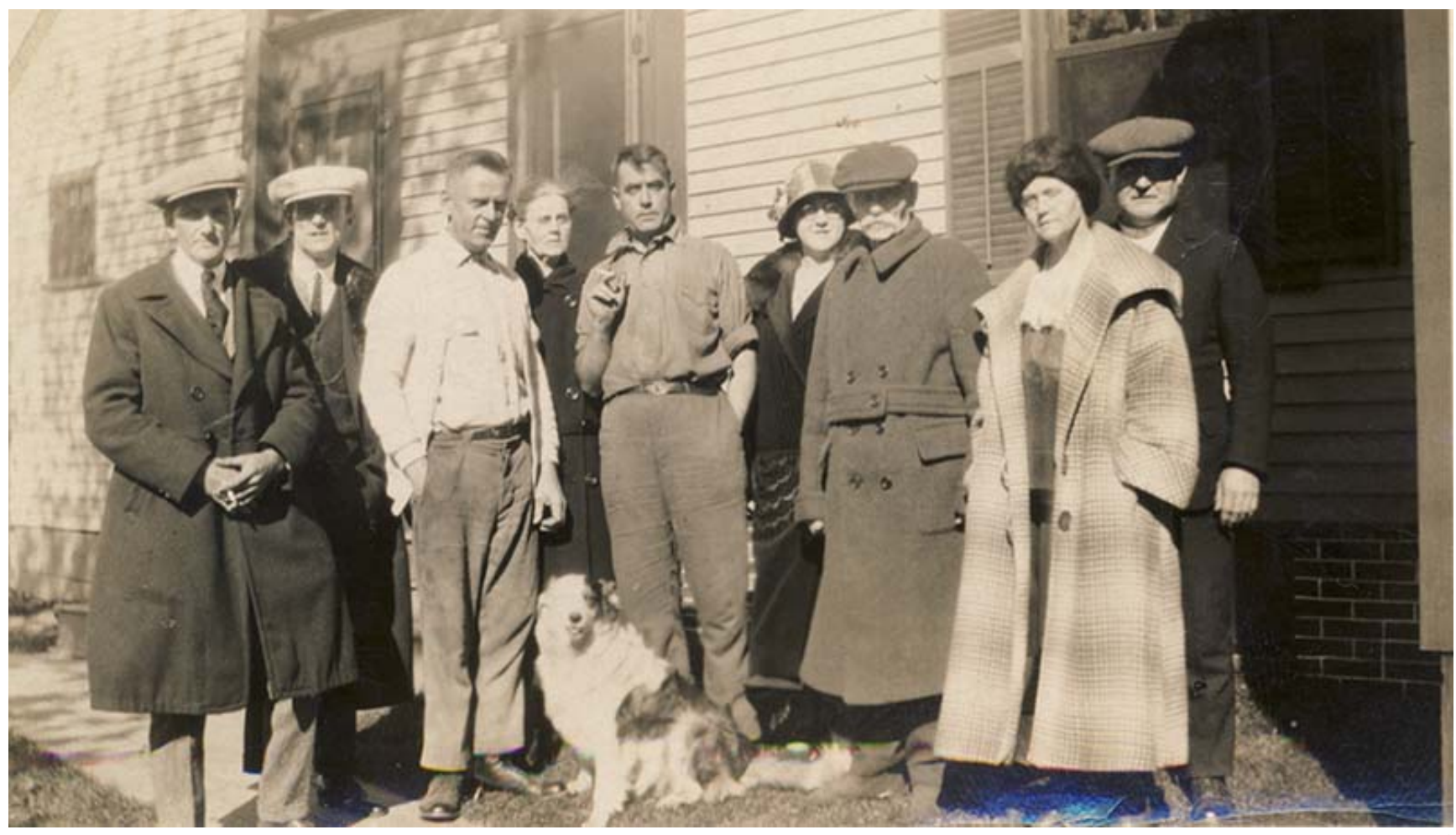

Figure 3 


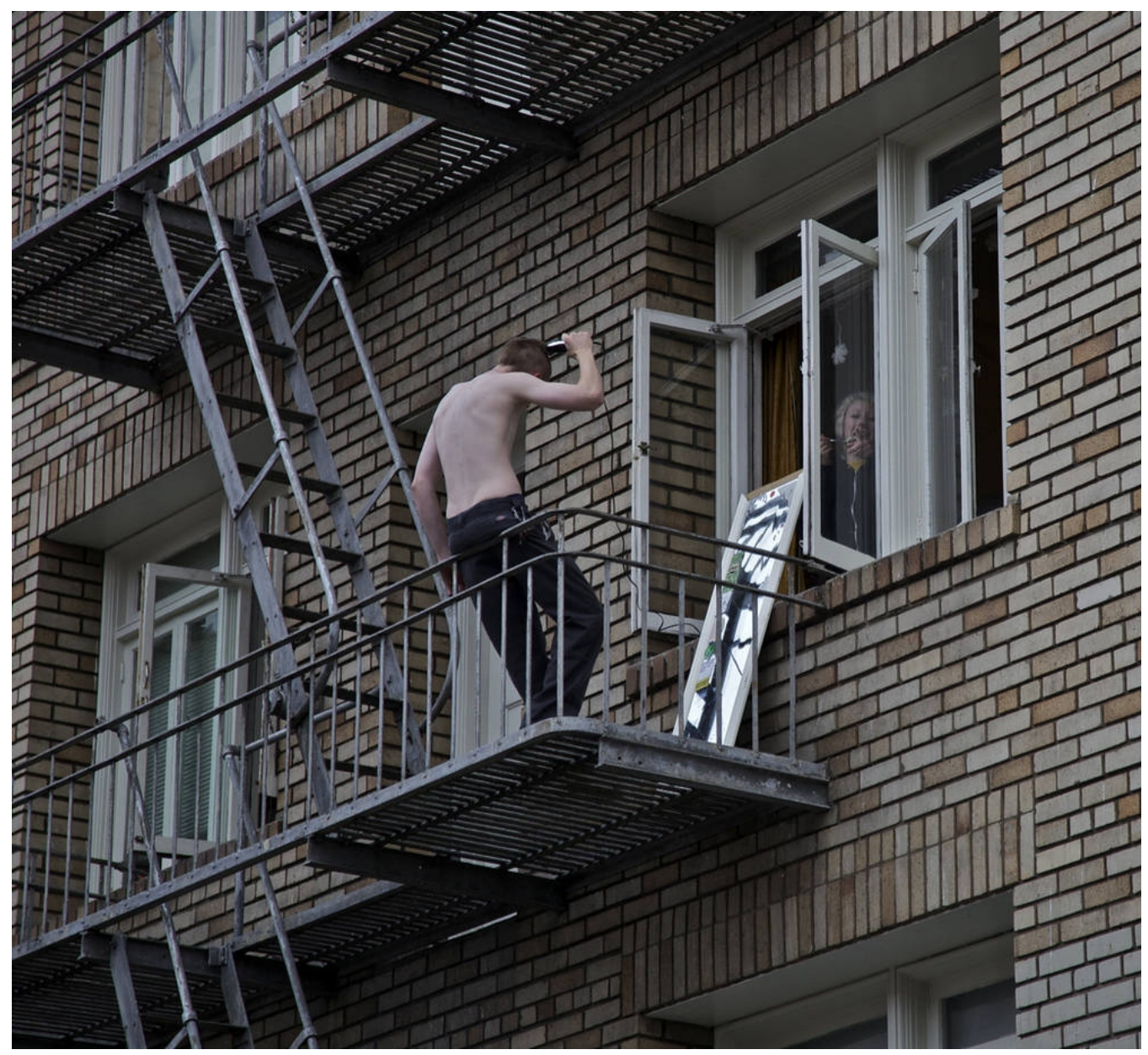

Figure 4

Continuing with building a visual reservoir to pull from in order to help me connect on a deeper

more visceral and emotional level with Tom, I set to the streets of Morgantown to find some bits of the

city that would resonate with Tom's world. Though I have spent time living in multiple large cities and have traveled through many, it is not an experience I identify with given a strong personal preference for the country living. My primary experiences in city living also come from a very different landscape as I have not lived in any areas where there are the type of brownstone tenements that would have been common in the Wingfields' neighborhood. So to give myself a visual to connect to I searched for the Wingfields' fire-escape in the real world. I did eventually find a decent representation here in Morgantown, West Virginia. Upon finding this home-base for Tom, his fire-escape, I gave myself time to both absorb the experience as well as capture a few photographs to take with me that would act as 
catalysts to transport me to that place whenever it was necessary to find that connection. Below are the two photos I found myself drawing on the most for this purpose. I imagined the building pictured on the left (figure 5) as my home, while the yellowish building (figure 6) was a continuation of the block.

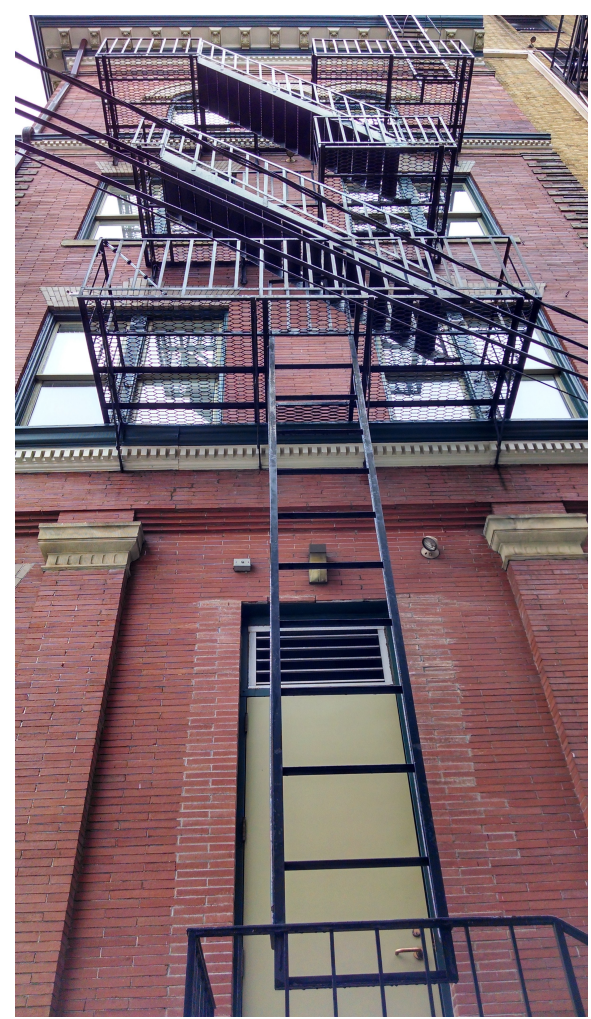

Figure 5

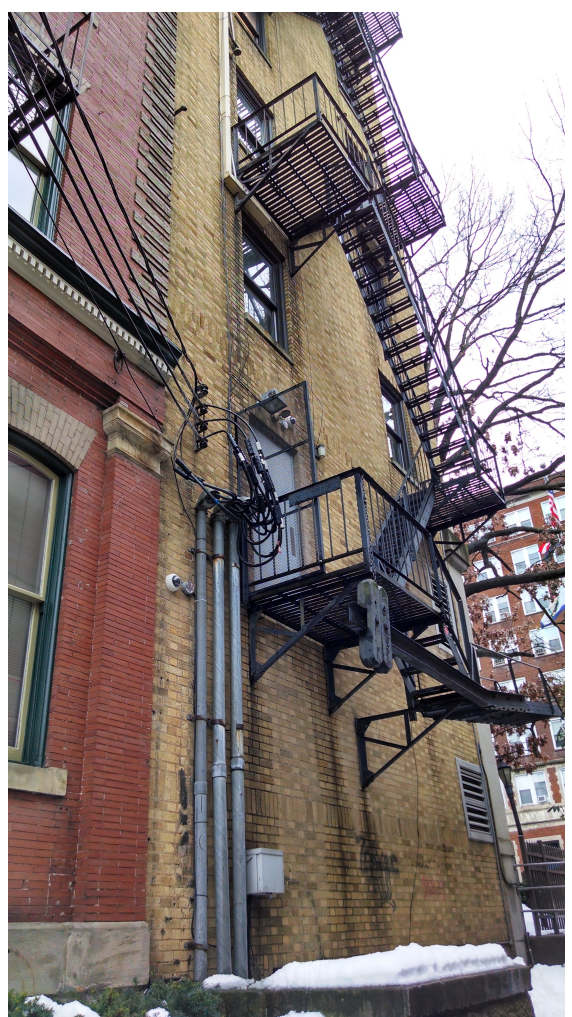

Figure 6

Though these buildings are clearly cleaner than would be expected of the Wingfield's and have a bit of a modern stylistic flair, they still served as a great experiential background against which I could set Tom's inner world.

Smoking was one other area with which I had very little real-world experience, and one that I felt I needed to get into my skin for Tom. Tom is seldom without a cigarette and, in our concept, lived in an ever-present haze of time that clouded the memories he was presenting, so smoke was an inextricable part of the play. In a world where a young man is desperately trying to break free from a trapped existence he has very few real escapes and his cigarettes give him a momentary respite from the stress of the world closing in around him. Not being a smoker and with smoke being such a big part of Tom, this was something I could not afford to get wrong. In my observations of smokers, I found 
that in order to effectively imitate smoking, one must establish a level of ease and a sense of ritual. In order to accomplish this I did some research and found an herbal cigarette and filter combination that would allow me to learn to smoke and establish a habitual pattern while greatly reducing the negative health effects associated with traditional cigarettes. I made a point to join the smokers in our program on smoking breaks so that I could set my habit and get used to smoking. Though this did help inform my performance to a point, at the last minute the director changed the concept from using the herbal cigarettes to my original impulse of roll-your-owns, however, due to University policies that disallow smoking on campus and strictly limit the use of fire on stage, we had to use the roll-your-owns without actually lighting them; so actually learning to smoke ended up being somewhat a waste with the exception of some of the fluidity that I had gained in dealing with cigarettes, lit or not. However, being unable to actually smoke may have taken away a large portion of the realistic action, but since we had gone with roll-your-owns, there was still an excellent physical and accomplishable task that would become a part of the escape for Tom and of my physical connection to him.

Beyond image and real life experience research, there was much book research that went into building the role of Tom. After all, Tom Wingfield is a poet, a reader, and a shade of one of America's greatest playwrights. This dynamic was very difficult for me as I do not write poetry and honestly have little love for reading. As much as I love stories and storytelling, as would be expected of any actor, my attention span is extremely limited for even the greatest of writing. I tend to gravitate more towards the visual and auditory forms, so this was an area I needed to be very vigilant about working on throughout the process. That said, I ordered an enormous stack of books that mirrored the poetic and short story tastes of both Tom and Tennessee as well as one semi-autobiographical account and a biographical account of Tennessee's life titled Tom: The Unknown Tennessee Williams by Lyle Leverich. Some other titles used for my research included Memoirs, Notebooks, and Eight Plays by Tennessee Williams, as well as a whole host of books featuring the works of playwrights and authors that influenced Williams 
according to the books listed above. One book in particular that I carried with me on a daily basis, and used to inspire writings, was The Complete Short Stories of D.H. Lawrence (whose works are directly referenced in the text during a fight between Amanda and Tom in scene three). This book's influence helped me to focus on the days that it was particularly tough to find the motivations behind and my meaningful connections with Tom by providing me a direct bridge in to Tom's daily world.

In the spirit of furthering my engagement with the poetic side of Tom, I decided it would be best to go beyond reading and create my own writings as well. In order to accomplish this I kept a leatherbound journal with me from roughly the second week of rehearsal through the end of the show's run and even found ways to incorporate my journal into the show as a useable prop. This journal was a place for me to explore, work on poetic writing, express my uncensored inner thoughts and emotions, and to externalize observations about myself, Tom, and anything else that may have entered my mind at the time. By the end of the rehearsal process and the show, I had forty-two full pages of writings, of various types, that closely reflected my place in the process and the world at the time. Another major benefit that came from having this journal was that it also served as a wonderful grounding tool during the show. During the second scene, I was positioned as a specter on the fire-escape overseeing the world of my memory. This time allowed me to take out the journal and dump any outside business that had come onto the stage with me. It also gave me the opportunity to purge myself of any stresses from the first act and write my way more deeply into my character and the play to give myself a more personal grounding in the story night after night in a way that adapted to exactly what I needed depending on the day. 


\section{$\underline{\text { Rehearsal }}$}

The rehearsal process for The Glass Menagerie was relatively straightforward and simple in format given that this show has such a small cast and our regular and honest interaction proved imperative throughout. In order to examine and explore this rehearsal process effectively, it will be broken down in to these three primary areas:

1. The standard format of a typical rehearsal.

2 Elements of this process that were unique.

3. My personal goals, focuses, achievements and challenges within the rehearsal process.

\section{Standard Format}

The format of rehearsals was determined early on in the process by our director, Kathleen Amshoff, and continued on into the run of the show. Having such a reliable process was nice as it allowed all of us to get into a rhythm and gave us the ability to fully prepare and plan for rehearsals.

The format of the rehearsals was very straightforward. Everyone was expected to arrive at least five minutes early, ready to work. At the start of rehearsal, always exactly on time, our director would call us all into a circle where we would begin by stretching as a group and then follow up stretching with some sort of a group game that would help us build our focus and awareness. Every rehearsal the leader of these exercises would change so that in the course of five days each person (including Amshoff) would lead the stretching one day and the game on a separate day.

Following the group games, we would then break into specific scene work, with the exception of the beginning and end of the rehearsal process - more on that later. The scenes to be worked were generally communicated to us early in the day by way of email and call board so that we could theoretically prepare the scenes prior to our arrival. Once into the scene work we would begin by running the full section to be worked. Generally we were allowed to complete the section and then 
Amshoff would come to us with notes about what she had just seen and would then go on to work the specific sections within the scene that she felt needed attention. If there was still enough time in the schedule to continue to work that scene then we would run it all the way through one last time in order to help try on the adjustments in context as well as cement any changes. This format remained the same from about the third rehearsal all the way up until about a week before the show, when the rehearsals consisted of simply running the show start to finish and receiving notes on the overall performance.

For the most part, rehearsals were well run and highly productive each night except that all members of the ensemble were present for nearly every rehearsal for the full duration. Though I believe this was unintentional and a result of the inevitable changes in rehearsal plans that occur during rehearsals, it was not the most efficient use of actors' time. Unfortunately, the majority of this burden fell to Bryan Staggers (Jim O'Connor), whose character does not even appear in the play for the first three-quarters of the show, meaning he was saddled with a lot of idle time watching the other actors rehearse. On the other hand, luckily for me, my character is in the vast majority of the scenes, so this seldom happened to me allowing for the bulk of my process to remain fairly efficient and highly productive throughout.

\section{Unique Elements}

Despite the fairly straightforward and traditional rehearsal process outlined above, there were some elements that Amshoff built into our time developing the show that were unique to her style of directing. Though some of these exercises were more helpful for me than others, they all helped in furthering and deepening our work to one degree or another. The primary unique elements of the rehearsal process were introduced within the first four rehearsals. These four rehearsals were broken up in to two reading rehearsals followed by two rehearsals that were dedicated completely to improv scenes.

Though we never really strayed from the routine of beginning each rehearsal with a stretch 
session and a game, in the very beginning we followed the warm-ups with a table read, which is often customary. However, Amshoff's process diverged for the next several rehearsals as we conducted a very close read in which the entire cast read through the text with the director and any individual at the table could stop the reading at any moment to ask questions or discuss points of the script with the director and the fellow cast mates. This was a very helpful technique that allowed us to flesh out the text as a group and arrive at a fairly consistent understanding of our world together.

One result of the close reading was a list of specific relationships and events that were not fully fleshed out or - in some cases — present at all in the text. From this list, a second one was compiled of improv scenes that were to be explored in order for us to build these shared memories organically as an ensemble. For each improv that we did, Amshoff would announce what it was we were going to explore, such as how Amanda first met her husband. Once we knew which event was to be explored, Amshoff would send the character involved into the hall (if more than one was involved she would determine if it was necessary to send one or both out, generally not to the same place). Then the remaining ensemble members, in collaboration with both Amshoff and the stage management crew, would build a physical scene for the world. Having the scenario and the place set, Amshoff would give each of the remaining cast members a task, objective, and or motivation as a specific character (whether it be one from the play or a newly invented one for necessity). With everything in place, Amshoff would bring the character(s) in from the hall and the improv would begin.

Tom was a part of five exploratory improvs. Below I have listed each improv that pertained to Tom and what my take-away was from each exercise.

\section{Tom and Laura as children.}

In this improv, Laura was very soft, nurturing, and above all playfully fun. Reflecting later in my journal I wrote that this element really helped to feed in to Tom's attachment to Laura as well as some of the guilt I feel now given how far she has fallen from being my nurturing older sister. 
Something else that really struck me in this improv, since the scene began with Laura and I playing followed by mom entering to tell us that our father would not be coming home anymore, was how similar this moment was to the day my parents told my older sister and I that they were getting a divorce. Just as in my personal life, I found that improvised Tom was too young to really grasp what was going on, so I continued to play with the toys I had with me (in the improv it was Jeff the glass dog and in life it was a Lego spaceship). There was also a sense that something big and sad was going on that I bought in to in both cases, but didn't really understand the meaning of the situation except for that everyone else in the room was sad too. Discovering this tie was very beneficial in informing my performance in that finding out something of that nature and magnitude at such an age of limited comprehension allowed me to deal with the whole event in a bit more detached and callous manner whereas my older sister was hit hard by the news being just old enough not only to grasp what was happening, but also to question herself in the whole equation. The result, in both The Glass Menagerie and my personal experience, was that the difference in how we dealt with this news reflected in large part our capacity to receive it; it took a large toll on my sister while creating a tacit alienation for myself.

\section{Tom's first night out and coming home.}

This improv was tough. It began at a bar after work and then continued into the home. Throughout the improv I had a strong sense of restlessness, as if there was nowhere that I really belonged and that I did not really have anybody to belong with. I felt very alienated from the world around, depressed, anxious, and above all else a desire to disappear. In reflecting on the experience, one of the things I put in my journal regarding the feeling I had while out at a bar in Tom's world, was that I felt as if "I've nowhere else to go, nothing else to, and don't want to be alone." Upon getting home I was greeted by my sister, which brought a wave of warmth and happiness to me. Unfortunately, during a nice conversation with Laura, "my tyrannical bitch of a mother comes screaming in to try to impose 
her world and ruin the only connectivity I have in mine." Clearly, this journal entry shows how negative interactions with my mother were in the beginning. This is something that, thankfully, Amshoff focused on tempering so that Amanda was not a full-time category 10 bitch tornado by the time we opened the show. The result of this direction allowed not only for Amanda to be a more complex character, but for me to emotionally invest in her. Such emotional investment is absolutely essential in a familial relationship such as that of Tom and Amanda if there is to be any realism to it that will garner the emotional investment of an audience.

\section{Dinner with mom and Jim.}

Being that this is an event that occurs within the time frame portrayed by the play but is skipped over in the script/performance, meaning that the action of the play shows the beginning and the end of the meal but nothing that occurs during, we felt it was very important to the continuity of the play for our characters to have this event occur through the improv. Interestingly, it was not so much what happened in this improv that helped me to gain further insight into Tom and his view of his world and the people in it, but rather the fact that I was at a table of two conversational giants with very little to say, so it gave me a lot of time to just think, absorb, and be present in that moment with those people. Though this is always the eventual goal of the state of an actor for performances, it has been rare, in my experience, to be able to find myself so deeply immersed in that state at such an early stage in a production's development. During this time in which I fully inhabited proto-Tom for the first time (or rather let him fully inhabit me), it really struck me just how desperate his world is. Tom has few (if any) friends, a poor relationship with his family (in spite of the great sacrifices he makes for them out of love daily) and has nothing of his own to show for it. Tom really has nothing of his own in life. Even his typewriter, one of his only escapes in life, must be shared with the others in the house and his books are on loan from the library. The only things that are truly and completely his are his clothes, his writings, his cigarettes, and his dreams of what else could be; three of which he is often criticized for. 


\section{After dinner dishes with mom.}

This improv was another that was based on an event that occurs in the play but is not seen by the audience and therefore not explored in the script, leaving a big hole for us as actors and characters as to what happens in this unrepresented void. This moment started out cordial enough, after-all it was a lovely night and mother was in a rather pleasant state as a result of something I did for her. We had some nice banter and I fantasized about the idea of mother finding a man and letting Laura and me off the hook to live by our own devices as a result. However, this fantasy was abruptly destroyed when Amanda mentioned to me how funny it was to her that I coincidentally brought over the man with whom Laura had been infatuated with for years, to the point of having kept a program from a play he was in at their high school next to his photo in the yearbook. Upon seeing her longtime crush at the door with me, my sister immediately began to panic. She had just been ambushed by her high school crush whom she never really got over and at a time when mother's pressure is being exerted on her at maximum force and she is at the peak of her anxiety. I could not think of how she would survive! This then led to the fear of what might happen to her if she were to get wrapped up in this dinner and he were to reject her. I did not know how I could live with myself if that were the case. This whole thought train put an immense sense of pressure on the event in that all of this could end neutrally, but

more likely either in a devastating heartbreak for the one that I love most in this world, or, maybe, just maybe, a happily-ever-after for my sister.

\section{Sick Tom as a kid with mom.}

This improv is the one that affected me the least. Though it did help to find a point in Tom and Amanda's relationship where we were not at odds and her smothering nature was somewhat endearing, as it all came out of love for her little boy, the actress playing Amanda, Stephanie Freeman, was openly critical of my interpretation of Tom, which made it very difficult to work openly and freely in a productively vulnerable improv. Her outspoken opinions of other actors' work would become a real 
sticking point for both myself and some of the other actors involved in the show which really limited the amount of group trust and buy-in.

After having been in rehearsals for a couple of weeks, Amshoff shook up the normal routine a bit by scheduling a round of individual rehearsals. In these highly beneficial individualized sessions (roughly 45-minutes each in rehearsal and a personal sit-down discussion outside of rehearsal), we were able to discuss the text openly and critically, finding my strengths and weaknesses as and actor and how best to use those in order to help accomplish Amshoff's vision for the play. During these rehearsals, we also were able to work with Associate Professor of Voice Laura Hitt on vocal technique for the show, based on what each of us most needed. In my case, working on a way to yell safely, given the vocal intensity of some of the confrontations between Amanda and Tom, was paramount, as was the ability to convey the meaning and purpose behind each of Tom's monologues with particular focus on the poetic elements. This was also an area where Amshoff and I spent time, breaking down each sentence, paragraph, and speech looking at the active purpose and tone as it relates to the audience. The purpose of this work was rooted in the idea that the effectiveness and aliveness of these monologues is critical to the show, and, as I mentioned before, I do not have the strongest of poetic backgrounds.

\section{Goals, Focuses, Achievements and Challenges}

Tom Wingfield was a fitting challenge for me as my thesis role as it allowed me to work on two of the most important factors necessary for me to continue to grow as an actor. The first being my ability to, in the words of my first great acting teacher, Larry Hecht, "just play". The ability to shed all the excess pressure, stress, and self-imposed expectations that move us farther and farther from natural interaction and emotion on stage is contained within that very simple piece of advice. Know the words, own the emotions, and just play! The second major focus was, as mentioned before, developing the ability to reach down inside myself and allow my personal self to come out in my acting — rather than putting on some false exterior. In order to work on this particular challenge I had to keep myself in 
check at all times during the rehearsal process so that I could continually monitor and hold myself accountable for being myself and rooting Tom in my truthful and honest self rather than running from my own skin in order to inhabit Tom's hollowly. Combining these two major challenges allowed me to work towards and, to a certain degree, achieve a great deal of improvement in my ability to just myself be on stage, open and vulnerable, and simply live the family relationship that I already know so well. This was an extremely rewarding experience and one of the most difficult accomplishments I have ever achieved in my acting career. In a strange way, letting oneself be so much of what is on stage as the character is both the most difficult thing one can do in acting but is also the easiest way to find truth, ease, and play on stage.

Another major challenge that I had to face in order to build the role of Tom was being cast late. As the casting fell for this show, I was not the original choice for Tom Wingfield. Though I did receive a call back and was a clear top candidate for the role, Ben Roberts was the one who originally received the role. Due to extenuating circumstances, Ben had to back out about a week before rehearsals began, which is when I got the call. Being offered the role was a spectacular surprise but also a real shock, not just because of the unexpectedness of the events at hand, but also due to the fact that I stepped into such a prolific role a week before formal rehearsals began, over a month behind the rest of the cast, with the expectation being that the cast was to be off book from the first rehearsal. Luckily, we blocked the show almost immediately, which greatly helped the memorization process for me. I am a very physical learner, so the curve was sped up greatly compared to just straight memorization or dialogue work by allowing me to connect the text with my body's movements/actions early on. Even with the memorization boost given by working in this manner, getting off book for such an enormous role in such a short period of time was a monumental challenge. Unfortunately, due to the work load of the MFA program outside of shows, I was unable to be completely off book by the first rehearsal, though I was quite close. I was extremely proud of this achievement, which allowed all of us to work at a much 
deeper level right off the bat and reach a level of comfort with the memorization by the run of the show that I have not paralleled in any other show to date.

The matter of poetic language, which I have spoken a bit about previously, was not only a further large challenge for me in this role, but has also been one of the ongoing challenges of my education here at WVU. Poetry is not my thing. I understand it well enough and have had to write it in the past, but I often find poetic language to be unnecessarily precious and the subjects of poems and poetic speeches often miss their mark with me. There are, and always have been, some great exceptions to my general disinterest in the art of communication by way of poetry, such as Robert Frost, e.e. Cummings, Homer, and, above all else, Sam Shepard. These three authors and one bard tend to write in a way that resonates deeply with me through a more primal and visual style than I find with many other poets. It also helps that these poets have many elements of their works that come from parts of nature and life that I can relate to well. The west, adventure (something I share at my deepest core with Tom), military, grit, epic struggle, cars, guns, comfortable isolation/connection to the wild, etc.; all subjects that inspire and enthrall me. Outside of the aforementioned limited group of poets, I have spent little time with the form, so taking on a role such as Tom, whose speech is not only steeped in poetry but who is an actual poet, was about as big a challenge as I could undertake in a role.

My work on expanding my poetic knowledge and abilities started early in my time here at WVU when the faculty mentioned my apparent ill-ease with poetic language in an early evaluation and suggested that I take one of the poets that I connect with and spend a considerable amount of time reading and speaking their work. For this exercise, I chose Sam Shepard, whose world most closely collides with my rough and tumble lower/lower-middle class upbringing in the deserts and woods of the west. Within about two weeks I finished two full volumes of Shepard's poems and one of his anthologies of short stories. This kind of immersion not only helped to break me open to a higher level of comfort and comprehension than I have ever had in poetry, but it inspired me to begin writing my 
own work. Though none of my work is destined for an award, finding the permission in Shepard to write about the not-so-pretty and seldom poeticized parts of life that stray far from the experiences of most art and artists that I have encountered (a group I do not personally identify with, preferring the mentality of an artisan or highly skilled craftsman when it comes to my work) pushed me past my blocks to begin opening myself to poetry. Combining this new found freedom with the genius methods of e e. cummings in his formatting — specifically for further poetic and visual effect—allowed me, for the first time, to express myself truthfully in a manner that has, for most of my life not only been inaccessible, but also scared the hell out of me.

From the above work with poetics and poetry, my abilities and comfort with poetic language began to open up and build in a way that allowed me to approach all of our work throughout my time here from a more emotional and intelligent standpoint than I was capable of before I came to WVU. Combining my personal work with the work in class, particularly on poetic dramas and Shakespeare, I came to the role of Tom equipped to take on the challenge, though still far from where I needed to be in order to succeed. Knowing this, one of the first things I did after my initial read of Tom was to look into Tennessee Williams to see who his major poetic influences were as well as which ones were specifically mentioned or alluded to in The Glass Menagerie. In my research I found that D. H. Lawrence and Hart Crane were the authors I should focus the majority of my work on. I took this list of poets to the internet and went on a shopping spree, ordering full anthologies of not only these authors, but also of other great poets and playwrights such as Robert Frost, Arthur Miller, and Eugene O'Neill. These anthologies of poems and poetic stories served as a transformation base where I could take all of my root work and piece it together with the similarities I had found between myself and Tom in order to build the parts where we differed onto that base. At all times during the run of the show I either had one of these books (most often The Complete Short Stories of D.H. Lawrence) or Tom, by Lyle Leverich, the biography of Tennessee Williams, on hand. This constant exposure to the poets that 
influenced Tom/Tennessee and the life of Tennessee, so much of which informs this play, helped me to lay a very solid, colorful, and nuanced foundation from which to work.

Though the readings mentioned above were invaluable in my work, Tom was not simply a reader of poetry, but also a writer. This meant that I needed to revisit my abandoned practice of writing poetry. Over the course of rehearsals and the show, I recorded more than thirty pages of poems in my small, leather-bound journal. This journal went everywhere with me just as I imagined Tom's journal did with him. It was a private compendium of both visible and invisible poems. I say invisible as prop master, Jane Ryan, made the choice to exclude ink from the typewriter and pen that was allowed on stage (for reasons that I did not and still do not know), a choice that the director fought against alongside me initially, but later chose to back for the final production. Though I was denied real ink for my typewriter and pen for later rehearsals as well as the run of the show, I never fake wrote. During the period that I was forced to work without ink, I took care to use enough force with both the pen and the typewriter to imprint the paper with pressure worn ghost letters. I attempted to recover some of these ghost writings, but the time between the production and present have caused the pressure marks to fade. This collection of works and constant commitment to writing helped me to deepen my connection not only to Tom and his world, but to myself in challenging myself to come up with new material every day and new ways to express myself every time. The level of character work that I achieved would not have been possible without this intense work in poetry and poetic language, and as a result this work will go far beyond Tom to benefit my personal communication as well as my text work for the rest of my career.

In addition to the text work and writing to improve my use of poetic language and maximize my ability to truthfully engage the audience, much time was spent developing my physical presence as well as breath/voice, two essential elements in finding a natural ease and self on stage. In order to work on the breath and voice component we were very fortunate to have Laura Hitt come in to do special vocal 
sessions. During these sessions, Laura helped me to direct the focus of my breath and my voice to project emotions and the text's poetry by way of deeply visualizing the images and emotions of the language one phrase at a time before speaking. This work was slow, but as we worked each phrase I gradually increased the speed and ease of line delivery while still imbuing the lines with the richness of the desired emotion and image to be conveyed to the audience. One particular comment that helped me greatly during the process with an issue I have struggled with throughout my time here at WVU (wasting power on exhaling before speech or in between speech), came from Professor Jim Knipple during a studio scenes session while he was giving notes to another individual. Professor Knipple commented on the actress' work saying that she needed to remove the breathy bits and extraneous exhalations in her work. In his critique he said something near to: “you build up great power, but every time you get breathy or exercise an extraneous exhale, you are just exhaling all of your power. As such, your exhale must be on the line and used only for the words to keep that power where it belongs, with the actor and the language where it can be used to advance the acting". For whatever reason, even though this is not far from the instruction given by many faculty members here, the image of exhaling your power really stuck with me and illuminated, clearly for the first time, this issue. This idea that if I combine the work I was doing with Professor Hitt with the advice of Professor Knipple, I could consider the relevant image, act on the line without giving away the power in between them, and it could (and did) help me to clear some major hurdles in my acting issues. As a whole, this adjustment allowed me to advance to a new level of self-perceived power, presence, and truthful comfort on stage.

Moving even farther with this work took me deep into the physical realm of acting. This has been another area that has required extra effort in my time at WVU, as finding true ease in a character's skin and on stage has often been quite difficult. The reason for this is quite simple: prior to this role, I never allowed enough of myself into the character and enough of the character into me. One of the biggest blocks that helped to support that divide was purely physical. In the past I have always worked 
hard to build a different physicality for each character and have realized that any time I have not created a comfortable physicality to this new and individual person, I have not found the character. However, in the past, these physicalizations, though helping to build the character, have often distanced my personal self from the work too far to allow for any meaningful level of rooted work to occur. Thankfully, with Tom this was not the case. With Tom, I was able to take the similarities that we share and use them as permission for me to allow my own physicality on stage. This worked to a point, but presented itself as a slightly fabricated representation of my true physicality; that is, until we got my fire escape. The day the fire-escape arrived on set, I was feeling particularly loose and carefree after an extremely exhausting week and nearly no sleep for about four nights, so my inhibitions were low and my need to play was high. As a result, in the middle of a scene, the blocking called for me to ascend the fire-escape, but instead of simply walking up it, I dove through the metalwork from the stage to about halfway up the stair and used the railing to launch myself the rest of the way up, pausing only briefly at the top to suspend myself and rotate coolly down into my new direction, as if dismounting a portion of the Marine Corps obstacle course I used to run at Camp Pendleton. Immediately after the scene, the director remarked excitedly that that was perfect, that was Tom, and I could feel exactly what she meant! From that moment forward, something just clicked and a natural, relaxed but engaged, and connected physicality flowed through me every night. It felt natural, effortless, REAL, and never awkward. This physicality was only furthered every night that I worked with Jim. Our personal and stage rapport set us both at a playful ease that, over the course of the rehearsals, let Tom sink in-to my core and for easy comfort to feel OK on stage for the first time in my career.

Moving beyond the physical, mental, and mechanical challenges, there were some other major obstacles I had to face that, unfortunately, kept me from reaching the level that I had desired to reach with the role. These particular issues were simply a matter of logistics forced on us by the demands of the MFA program. Our schedule in school seldom allows for us to warm up before arriving at rehearsal 
or call and the rehearsal format, as well as required pre-show group work allowed for very little individual warmup, a major problem for me. A large part of the reason that this was an ineffective format for me is that the majority of our group warm-up time was dedicated to games. I have always found that games do little to warm me up, particularly when not all of the cast members take the games seriously. In the group warmups there was also supposed to be a physical component that would both stretch us out and warm-up our muscles and voices. Unfortunately, given varying fitness levels of cast members as well as differing focus levels for exercise completion, the warm-ups we did as a group were beneficial for some, but did very little but take away from personalized warm-up time for others.

Another problem with this format is that it was instituted with the expectation that we show up to both rehearsal and shows with all of our individual work done prior to rehearsal, which was wholly unrealistic unless we were to skip dinner, a very unhealthy and unproductive prospect that, for me, results in difficulty both performing and remembering lines at my full potential due to my body's extreme reaction to low blood sugar and iron. This is one challenge that I was not able to overcome and simply had to be pushed through being a matter of circumstance. Unfortunately, this particular type of compromise has pervaded my time at WVU. This has been a result of the general mode of operation for the program being deeply intense in regard to the workload-time balance, which has created an unfortunately pervasive culture of necessary compromise. I often found this compromise be in conflict with the level of standards I hold myself to in the professional world for shows, an extremely frustrating reality. I will say that, though often inhibiting, the major benefit of this level of workload, is that it has forced me to become significantly more efficient with my work than I have ever previously been. Also, I have developed a meal plan that allows me to stay relatively healthy even with such a tight schedule. Having pre-portioned, ready to eat, high nutrition meals and snacks with a wide variety of nutrients on hand at all times allows me to keep a stash of sustenance that allows me to get by during the couple of breaks in rehearsals even if I have missed a major meal. I believe that the schedule, as 
designed by our department, was likely done so with this intention and that these habits in my work flow and personal care will go to benefit me throughout my career.

Along a similar vein, the six-day-a week rehearsal format made it very tough to keep up in school and work while also giving me little time to catch up with the other cast members who had had more than a month more to prepare for their roles than I did. This type of rehearsal schedule also elevated stress greatly given the pinch it put on school and, in return, the pinch that school put on it. Not only did this pinch create a revolving door of conflicting work, but it also eliminated any semblance of free time outside of school, work, or rehearsals which would allow for the pursuit of further personal work and research as well as some de-stressing endeavors that allow actors to remove themselves entirely from the world of theatre and refresh themselves by engaging in activities that allow them to think, play, and recreate in a whole different way; an operation that is crucial in the lives of actors to maintain open creative pathways and maximize their ability to work at the highest level possible. In order to maintain sanity, I would often sacrifice sleep in order to take my dog for an extended midnight walk or grab a nice beer and enjoy in to an episode of Top Gear or Bob's Burgers. Though this was not always the most productive use of time and often fed my lack of sleep and work output, it was wholly necessary to in order to remain effective in my work.

One further logistical issue that we were contending with as actors was the process of notes. With a few exceptions, notes were seldom given to actors at the end of any given rehearsal. I found this to be very strange as doing so has been the practice for every show I have ever done in both my academic and professional career. Doing so allows actors to examine the notes and make the necessary adjustments that night while the work is still fresh in their minds. Instead, notes were generally sent to us late at night after our rehearsals or, more often, the next day while in classes or teaching, so we had little if any time to do much more than skim the notes prior to the next day's rehearsal, which was often on a whole new section, and, as a result did not give us much time, if any, to incorporate and solidify 
the notes while disallowing the ability to ask questions of the director regarding unclear or confusing notes.

In any ensemble there are bound to be challenges that will arise between ensemble members themselves, especially in an environment such as ours where we are together eight to twelve hours a day, every day, for several years in a row. Though our cast was pretty tight and relatively trouble free all the way through the process, there was one individual that was extremely difficult to work with. This particular cast-member had a very narrow focus and comfort zone that influenced rehearsals, warm-ups, and outside gatherings in a predominantly negative manner. This individual had a tendency to divert work or derail other actors whenever the subject matter would move to a serious place, trying to make everything into lighthearted games due to a personal discomfort with the conflict and difficult actions/themes contained within this play. This person also exhibited difficulty in accepting notes from the director without making excuses, placing blame, or calling the director's notes into question. On occasion, this individual would even go so far as to give other actors notes outside of the presence of the director to try to push a particular view or promote a particular interpretation. These behaviors eventually resulted in the specific needs of other actors or characters not being met or being undercut in a way that caused certain scenes to be unable to build or track the ideas/concept oft expressed by the director and fractured the spirit of collaborative creation and trust within the ensemble. Unfortunately, I feel that the director did not do enough to quell this kind of behavior, which resulted in a lack of closeness within the ensemble and prevented us from being able to do the level of work I know we were all capable of given a more disciplined, collaborative, and supportive atmosphere. Though it is unfortunate that our ensemble was not able to reach our full potential, our personal quirks and limitations are an integral part of what makes us who we are and helps to fuel our work, whether or not with maximum efficiency. In both this production and several others where I have worked in less-thanideal conditions, reminding myself of my own personal failures/challenges and actively working to 
foster patients and understanding in myself has proven to be the most effective way to help me focus on my own work to the best of my abilities while attempting to be fully present for my partners even in the midst of conflict or frustration.

The most difficult moment of the entire process, which heavily tested my resolve on the tenets I have just expressed, occurred during a cast-and-crew bonding dinner when the stage-manager announced that we would be getting to use the individual dressing rooms for the show as opposed to the large group dressing rooms. Since I like to be able to prepare privately, in my own quiet space, for roles such as Tom, I remarked that that was great news. My comment was met with immediate mocking laughter as well as several comments, from the above mentioned individual, to the tune of "I got into theatre because I actually like people," "silence everyone! It's time for me to prepare” while producing masking motions with their hands, and "of course you would prefer to be alone." I responded to the individual's laughter and comments by saying that we all have different processes and that there is no need to criticize mine just because it is different than yours, a comment that was met only with further mockery. At this point I told this individual that they were being extremely rude proceeded to block them out of my awareness for the remainder of the conversation, a move this individual took great exception to. Unfortunately this riff was not healed as I did not pursue the issue past that evening and they never offered any sort of an apology for her actions or comments. This unfortunate event, as well as how it was handled (or rather not dealt with) by both of us, only served to segregate the cast in to three effective groups: the actor whom I have been talking about, another actor who was well liked but did little to socially engage with other members of the cast, and myself along with the fourth actor who was truly a dream to work with due to their enthusiasm for the work, openness to play (while still maintaining a professional demeanor and ethic), and their willingness to collaboratively and openly work. This particular actor was very helpful in allowing me to achieve my goals of finding a physical ease and level of personal truth that I had never yet reached on stage, and I am thankful for their 
presence in the cast. I do regret that the previously mentioned actor and I never took the time to sit down and resolve our petty dispute; however, I am happy to say that we not only got through the ordeal and the process together, but that we have gone on to build a good working relationship that is still in place today.

\section{Performance}

The Glass Menagerie ran for a total of eight shows spanning from the sixth to the twenty-third of March. As a whole, The Glass Menagerie was one of the smoothest and most consistent show runs that I have ever been a part of. Largely, the credit for the show being so well prepared resides squarely on the shoulders of our director. Amshoff set the expectation for everyone to show up to rehearsal number one off book and ready to go (with a small amount of slide room for myself given the circumstances), blocked the show straight out of the gate, and made full use of the time allotted to us every day. Amshoff's drive and baptism-by-fire style meant that we were all comfortable with the show as soon as two weeks prior to opening the show and doing nothing but running it in repetition while starving for an audience more than a week before preview. By the time the audience showed up we had run the show in its entirety between ten and fifteen times as if it were a performance and, with the understandable exception of the greenest actor in our ensemble, had no nerves to give our first audience since we were just so thankful and excited to finally have folks to play for.

Despite the positive state we went into the run with as a cast, there is inevitably at least one rough show per run; in our case that show was the third performance. The show was so rough that it has been difficult for me to relive it through my journal even months later. At the time, I regarded this show as perhaps the worst of my life and I was not alone in the cast feeling as if the show was a total disaster. Our timing felt all over the place, the lines came out feeling foreign, and the actors, across the board, did not seem to be able to synchronize the characters, actions, and emotions. To top the whole experience off, the actress that played Laura, requested a new glass animal from the props department 
for the one that gets knocked off a table by my jacket as the punctuation to one of the most emotionally intense moments in the show. Our original animal (an elephant) was the only one of its kind in the set that our props master had procured for the show. This meant that we had to select a completely different animal (a giraffe), which changed the size and shape of the target for my jacket swing dramatically. These different proportions, and perhaps some mental psyching on my part as a result of the switch, resulted in my jacket completely missing its mark, causing the moment to fall completely flat, a nightmare on stage. At intermission I grabbed my journal in an attempt to write out my frustrations and clear my head for the coming act. At this point I comment in my journal that so far the show felt much like a football game when you are losing to a team that is nowhere near as good as you are but for some reason you just cannot find a way to stop them or get ahead. Though we tried to rally to pull the second act together with the hope that the intermission had given us the time we needed to right the ship and that the introduction of Jim with Bryan Staggers' fresh energy could turn us around, we were simply too far gone and eventually fell in to an auto-pilot push just trying to survive to the end with whatever level of life and energy we could squeeze out of what we and the show had left.

Though this performance was a very difficult one to get through, it became a catalyst for improvement for the rest of the run and had an overall positive impact on the attitude and work-ethic of the cast as a whole. For me, the third show was particularly beneficial in that it really helped to drive home a lesson that I had already learned years ago while working in film but that was always hard to ingrain in my beliefs and actions beyond an intellectual level: no matter how a performance feels, we never really know how it looks. The fact that after the show crew members who had seen the show nearly a dozen times said that they saw little difference in the performance and thought that, though a bit different, it was an overall successful and enjoyable show to watch began my questioning of my perception of the performance. This encouragement was furthered when a group of four students who had been in the audience that night requested to speak with each of the members of the cast 
individually to congratulate us on what they thought was an incredibly moving show. Their kind words and the apparent impact of the show on them drove home the idea that no matter how a run feels to you or how you believe it looks, you can never really judge how it appears from outside yourself and the world of the play particularly with any audience members who may be unfamiliar with the show and have no point of reference from which to judge your work or any particular show against the others in a run. That simple truth is a very important one to understand in order to take the pressure off oneself and reach ones full potential. After all, all one can really do is prepare for a role to ones fullest ability and then just go out there, listen and react openly and honestly with ones partners and allow ones instincts and preparations to guide and drive you and you can never go wrong. Different, yes, but wrong, no. In doing so you can help yourself to overcome one of the biggest enemies of the actor: his/her own internal judgment and commentary, which will always tend towards hypercritical, can never be used as a true gauge as to how he/she is coming across to the audience. After all was said and done, that show may have knocked me off my center, but those students gesture and the above solidification of the realization that I had years ago brought me all the way back. I ended up coming away motivated and ready for the rest of the show's run. Reflecting after the whole experience, I wrote: "[I am] feeling great now and really looking forward to tomorrow night now that all the dust has been brushed off. Onward and upward, or as Lyndsey Hailey (one of my improv teachers from the iO - Chicago) would say: 'here we GROW!"”

The fourth show kicked off a whole new kind of approach to the show after weathering the previous show's storm. As a result my prep-work became more intensive and more positive than it ever has been before. This resulted in a new way of looking at my work and the shattering of old patterns and superstitions that had been holding me back by pinning me to nerves and fear prior to a show. This new more focused, playful, and intense mental prep (a simple shifting of mindset and resistance to all but productive behaviors) is perhaps the most positive adjustment to have resulted from my work on 
this show. Unfortunately, the enforced group warmups only got more in the way with this new focus, but using that distraction as a time to confront negativity head on and convert it to motivation was a truly invaluable part of my overall preparation for the remainder of the shows. From this point forward there were few true challenges in the run since the prep was there, the motivation was there, we had all elevated our game after our rough run, and the whole of my fears and nerves had been vanquished by my own mindset. Now having accepted that those fears were fully groundless and nothing but a selfimposed hindrance that I could overcome with little more than the proper mental work and selffocusing prior to the show, there was nothing left to do but "just play."

\section{$\underline{\text { Evaluation and Outcomes }}$}

The run of this show concluded in a very fitting manner: as I left the stage door from the final scene it locked behind me providing an appropriately final ending to my Tom Wingfied and the entirety of the play. Just as with Tom in the play, I could never go back. Though the experience has passed and I can never return to that run, I leave it with no real regrets. As a whole this show was one of the most beneficial and transformative experiences of my career. Overall, my feelings on this show, my work with it, and some of the most beneficial outcomes can be best described by excerpts from my journal entry for show seven:

Though I am still battling myself to a point with judging my own performance and catching lines I think didn't come out right, or anticipating, but I am finding a great confidence and comfort that allows me to brush that off, settle back in and just breathe in the role.

Working at this school has really improved [my] audience relationship. Working in a space like the Davis there is no divide, no us and them. The audience is close, ever present, and perfectly visible which allows you to accept them as a comforting reality and really draw on their energy while practicing a fishbowl like one-way mirror.

Paraphrase regarding the final monologue: I finally reached a point at which I can really breathe 
the text and think through the arrangement of the thought clusters while simultaneously maintaining a soft focus on the world around me so that even the smallest surrounding details can be inspiration and inform the work.

So far, I have to say this has been a phenomenal experience for me and a great play to do. I think I have done well. Could I do much better, absolutely, always. [However] I think given the limitations on prep from being in school and where I am at in my evolution, I did about as well as I could. This show has been very beneficial in helping to connect me better with my acting [as well as increase my ability to] deal with nerves and my own head. ... Tomorrow we reach the end and I must say, I will be very sad to see Tom go, but will always look at this show as a landmark my career in the leap it helped me to make in my comfort [with] and approach to acting.

As stated in the journal entry, I do believe this role allowed me to make a leap in my work and even more importantly, my confidence in my work. Tom presented just the right mix of challenges for me to work on the biggest problems and hold-backs I have been wrestling with throughout my time at WVU as well as my career. As a result, particularly after the very difficult experience of show three, I have had a major shift towards positivity in my regard to myself as an actor and my abilities on the stage and within myself that will only allow me to improve as both a performer and a student.

This production also allowed me to make some discoveries about process that have never occurred to me until now due to the unique nature of Tennessee Williams' The Glass Menagerie. The power of observing one's fellow actors is one such discovery. Since this play is a memory play, all of the characters are as Tom remembers, and presents, and live within and come from him. As a result, each character within the play tells me a great deal about Tom and his inner landscape. With this realization, watching the other actors at work became a very regular part of my process and will continue to be, as that observation allowed me to make the kind of intimate and nuanced discoveries 
about my fellow actors'/characters' personal tendencies and habits that we pick up on in all of our day to day relationships in real life.

The other such discovery came out of Amshoff's constant quest for the color and detail in the individual characters and their relationships as a family. Until this show I had always approached roles trying to find the true inner emotions and thoughts of my character and how that influenced their outlook on the world, but I never realized how simplistic my interpretations had been. In the beginning of our rehearsal process the actress playing Amanda and I had very angry characters who were very bitter all the time about their relationship and situation, a trait I have seen in all the productions of this show that I had attended. As we worked with Amshoff and I discovered more and more similarities between Tom and myself as well as my relationship with my mother, I realized how much love there was in their relationship. Surrounding that love was also a desire for my happiness as well as for my mother and sister, a certain level of pride, a guardedness, and a desire for a better life, including a better relationship with my mother, but not knowing how to get there. All of these thoughts and emotions are incredibly complex and exist within Tom at all times. As a result of this complex psychological and social/familial landscape, as well as the fact that these thoughts and feelings have been attached to all of this after the events, by way of Tom's memory, none of them can escape entirely untainted by at least some level of reflective bias in their presentation. These emotions are also all but small threads that woven together with the rest of Tom's thoughts, emotions, and feelings make up the tapestry of his character and likewise for each of his relationships at any given time. However, much like a tapestry, the overall picture is formed by only the surfaces of the threads while the entire work is held together by many elements that are never seen and that duck in and out of the surface constantly and for varying lengths. This is much the same as the way that any given element of the character and the complexity contained within the relationships can take on an infinite number of shapes in nearly a moment, simply based on which thread has been exposed from the surface, cut from the piece, or lies beneath the 
surface threads as the main support. This is a level of complexity that every human and every human interaction has that I now have a far greater appreciation for thanks to this show. Applying this new found appreciation to my future work, as well as my everyday life, I can work to always find the threads; the happy in the sad, the vulnerability in the violence, the love in the hatred so that I can continue to color my tapestries ever more richly to give the audience the fullest and most complete representation of a true human possible.

The moment I realized that I had finally hit on something that resembled this coloring and found a way to bring myself to the stage through Tom, was during the first performance of the show's run. This was the performance that my mother attended. As I have mentioned before, there is a lot in Tom and his relationship with his mother and his family that I can greatly identify with, so having her in the audience was a very scary experience for me. However, having my mother there was also the best gauge of the performance for me. The reason I say this is that my mother knows me quite well and is privy to all the same knowledge and experience that I had with the family growing up that resonated with me in the show, and so if I had succeeded in connecting Tom to myself and myself to Tom, these similarities would resonate with her as well. It was not long into the show that I could hear my mom laughing from the audience in several places that no one else did. This lone laughter was not caused by anything comedic within the story, but rather from the recognition of us or my true self on stage. This indicated that I had achieved the me I had set out to achieve on stage. Following the show she had little to say, an unusual thing for my mother, but her few comments confirmed to me that I had hit the notes and plucked exactly the strings I had aimed to and no matter the perceived success or failure of my performance by anyone else, that to me made it a resounding success. I hit exactly the emotional mark I had aimed to hit.

From a process standpoint this show also yielded many gains for me. It helped me find the most beneficial vocal warm-up for my voice (the intoned lip trill), I was able to increase my experience with 
and exposure to poetic language, and it helped me to find the way into my vulnerability to let my true self on stage through Tom. This show also gave me the feeling of a dismal failure after show three, which, in turn, gave me the opportunity to bounce back and reevaluate my preparation and outlook. As a result, I found a confident positivity that is required to reach the level of play I set out to achieve. I was also able to allow myself to just let go and trust my preparation, instincts, and partners so that I could quit acting and begin simply and honestly reacting. This reevaluation of my preparation and process also helped me to begin work on eliminating one of my most destructive habits, left over from my earliest days of athletic competition, and that is a tendency towards superstition. I do not mean superstitions such as saying Macbeth or whistling in a theatre, as I have never had any belief in those fables, but more the establishment of superstitious patterns whenever I have a good show or rehearsal. These patterns generally evolve from an erroneous belief that if I do everything identically each time after the successful time, then all other times will be a success. This kind of routine leads to great deals of stress and can help fuel nerves rather than soothe them, which is their intent. After the disaster of show three, I went in the next day purposefully avoiding any and all routines I had followed that stem from that superstition, some going back ten years or more. This was a difficult task, but one that resulted in the removal of luck and chance as elements of performance in my mind while replacing them with trust in my preparation and self-actualization. This switch brought me to a place where I could really free my nerves and my sense of play that allowed me to enjoy acting in a stress-free way that I have not in years. I fully intend to take this mentality and its superstition-free pre-show preparation forward with me to every show that I do.

In regards to the management of the project, working with Amshoff was for the most part, a very positive and enjoyable experience. Her efficient time management and straight forward approach to text analysis and directing fit my personality style well, allowing us to work together in a very complimentary manner. Working with a director that had such a clear vision while also encouraging 
creativity and individual interpretation from the individual actors was very freeing in the way it gave a very solid foundation for us to grow and create from. Amshoff was also very supportive in helping us to find something in the text that I have never seen in any other production of The Glass Menagerie, and that was a true sense of family. Her concept and outlook were always guiding her in her communications with us to help bring out the color in each character and each relationship within the family. If the show were to be repeated I do think it would be important for Amshoff to discourage talk back during notes, actors giving notes to other actors, and to more solidly structure the group warmups to disallow the few negative elements that were discussed in the rehearsals section of this document from developing.

If I were to have to do the show over again, there is little to nothing I would change about the preparation and the process except for whatever changes may arise organically from the work. I would hope that in the future I will not have to deal with any detrimental behaviors to the process from other actors as I had to on this show. Though, when that eventuality occurs I am all the more prepared for it as a result of my experiences. I also hope that in the future I will have more time to devote to research, the role, and necessary rest in a way that will help me reach depths that were simply not possible as a result of the realities of being in the graduate program while performing. All things considered though, I could not have asked for a more positive show experience that helped me grow in so many meaningful ways as both an actor and a person. I would like to close by thanking my director, my fellow cast-members, and all of the crew involved for making it such an incredible and valuable experience, as well as the West Virginia University Theatre faculty for helping me to grow and expend my abilities and potential in a manner that has allowed me to come as far as I have and to realize how much farther I am capable of going. 
- Figure 1:

\section{Photo Credits}

"bata factory belcamp maryland 1930s." 193. JPG file.

https://www.flickr.com/photos/52067690@N06/5271611304/

- Figure 2:

"Handworkers on heavy boots, Hannah's Shoe Factory." JPG file.

http://www.alternatehistory.com/discussion/printthread.php?t=185434\&pp=20\&page=36

- Figure 3:

Hanna-Cowan family of Dover, N.H.. 1930. Dover, New Hampshire.

http://www.massmemories.net/images_mmrs/width800/37.42.2_800.jpg

- Figure 4:

Wilson, Erik. Fire-escape haircut. 2011. San Francisco, CA.

http://boingboing.net/2011/10/01/fire-escape-haircut.html

- Figure 5:

Harris, Beau. Brownstone. 2014. Morgantown, WV.

- Figure 6:

Harris, Beau. Brownstone II. 2014. Morgantown, WV. 


\section{Bibliography}

Leverich, Lyle. Tom: The Unknown Tennessee Williams. New York, NY: Norton, 1995. Print

Williams, Tennessee. Memoirs. Garden City, NY: Doubleday, 1975. Print.

---, and Margaret Bradham Thornton. Notebooks. New Haven, CT: Yale University Publishing, 2006. Print.

---, and Harold Clurman. Eight Plays. Garden City, NY: Nelson Doubleday, 1979. Print.

Lawrence, D. H. The Complete Short Stories of D.H. Lawrence. London: William Heinemann, 1955.

Print. 